\title{
scripted
}

Volume 17, Issue 1, January 2020

\section{Autonomous cars: A driving force for change in motor liability and insurance}

\author{
Katie Atkinson*
}

\author{
(ㄷ) (1) $(9)$ \\ (C) 2020 Katie Atkinson \\ Licensed under a Creative Commons Attribution-Non Commercial-No \\ Derivatives 4.0 International (CC BY-NC-ND 4.0) license
}

DOI: 10.2966/scrip.170120.125

\begin{abstract}
In this article, I review the legal and regulatory obstacles to the introduction of autonomous vehicles. I provide an overview of the key legislation which is relevant to the introduction of autonomous vehicles in England and Wales. I discuss the motor liability and insurance implications of the introduction of autonomous cars and the legal framework for the testing of autonomous vehicles on public roads. I conclude that there is likely to be significant volume of emerging legislation that car manufacturers and suppliers will be required to navigate as they launch increasingly autonomous driving systems. It is also likely that we will see an increase in the volume and complexity of litigation involving parties such as vehicle manufacturers, software companies, suppliers and mapping agencies.
\end{abstract}

\section{Keywords}

OEMs, product liability, insurance law, autonomous vehicles, ACES, automotive, Automated and Electric Vehicle Act 
* LLM LPC, BPP University Law School, katie.atkinson.100@gmail.com 


\begin{abstract}
"The increasing automation of our cars is transforming the way we drive and the government is steadily updating our laws in order to prepare for the future."

Jesse Norman, UK Roads Minister, 23 July 2018
\end{abstract}

\title{
1 Introduction
}

The automotive industry is in the midst of a technological revolution characterised by the convergence of new digital technologies with traditional car manufacture. ${ }^{1}$ The majority of major industry players are investing in technologies to enable cars which are autonomous, connected, electric and enable shared mobility (ACES). ${ }^{2}$ At present, the automotive industry is the third biggest spender on research and development, behind healthcare and software and electronics. ${ }^{3}$ This article focuses on a single aspect of this technological revolution - autonomy. According to forecasts by IHS Automotive, there will be 21 million vehicles with some level of autonomy sold globally in the year 2035 and nearly 76 million sold globally through $2035 .{ }^{4}$ Well-known companies such as Tesla Inc and Uber Technologies Inc are accelerating their investment in this field. Market

1 Mckinsey, "Mckinsey Centre for Future Mobility, Race 2050 - A vision for the European Automotive Industry", (January 2019), available at https://www.mckinsey.com/ /media/mckinsey/industries/automotive\%20and\%20assembly/ our\%20insights/a\%20long\%20term\%20vision\%20for\%20the\%20european\%20automotive $\% 20$ industry/race-2050-a-vision-for-the-european-automotive-industry.ashx (accessed 22 August 2019).

2 Jaguar Land Rover, "Future-type Concept - Jaguar's Vision for 2040 and Beyond", available at https://www.jaguarlandrover.com/news/2017/09/future-type-concept-jaguars-vision-2040and-beyond (accessed 30 July 2019).

3 Barry Jaruzelski, Robert Chwalik and Brad Goehle, "What the Top Innovators Get Right, Strategy+Business, Tech \& Innovation" (Winter 2018, Issue 93), available at https://www.strategy-business.com/feature/What-the-Top-Innovators-Get-Right?gko=e7cf9 (accessed 19 August 2019).

4 IHS Automotive, "Autonomous Vehicle Sales Set to Reach 21 Million Globally by 2035" (7 June 2016), available at https://technology.ihs.com/579470/autonomous-vehicle-sales-set-toreach-21-million-globally-by-2035-ihs-says (accessed 24 August 2019). 
leader Waymo anticipate operating a fleet of fully autonomous "robo-taxis" in New York as early as 2020 and have struck deals with Fiat Chrysler Automobiles and Jaguar Land Rover who will provide cars for the service. ${ }^{5}$ The topic of selfdriving cars has received significant media attention, due, not only to its technological significance, but also the social, legal and political implications of this revolutionary development in transportation. This article outlines the legal and regulatory issues surrounding the introduction of autonomous vehicles. It is intended that this article briefs readers in allied sectors on the motor liability and insurance implications of the introduction of autonomous vehicles and the legal framework for the testing of autonomous vehicles on public roads. It is worth noting that autonomous cars also have widespread legal implications in areas such as cybersecurity, collaborations and partnerships and data protection law, which are beyond the scope of this article.

The adoption of autonomous vehicles will depend not only on the ability of manufacturers and governments to address the legal implications of selfdriving technology, but also other key barriers. John Krafcik, the Chief Executive Officer (CEO) of Waymo, is reported to have said that he does not envision a day when autonomous vehicles are able to operate in all weather conditions without some form of human interaction. ${ }^{6}$ Key barriers include the cost of self-driving technology, public perception, the reliability of the technology in poor climatic conditions and how the existing vehicle type approval system is adapted to

5 Gwyn Topham, “Jaguar to supply 20,000 cars to Google's self-driving spin-off Waymo” (The Guardian, 27 March 2018), available at https://www.theguardian.com/technology/2018/mar/27/waymo-self-driving-taxis-jaguarland-rover (accessed 24 August 2019).

6 Mark Gurman, “Waymo CEO says Self-Driving Cars Won't be Ubiquitous for Decades” (Bloomberg Technology, 13 November 2018), available at https://www.bloomberg.com/news/articles/2018-11-13/waymo-ceo-says-self-driving-carswon-t-be-ubiqitious-for-decades (accessed 24 August 2019). 
accommodate certification of autonomous driving systems. At present there is no legislative framework dedicated to the approval of automated vehicles in the European Union. ${ }^{7}$ There is a procedure which enables automated driving systems to be exempted from current type approval rules and allowed on the roads, however the European Transport Safety Council (ETSC) has raised concerns about the lack of clarity surrounding the exemption procedure and the frequency with which this could be applied..$^{8,9,10}$

\section{What is autonomous driving?}

In 2014 the Society of Automotive Engineers (SAE) International published a new standard, J3016, identifying and categorising six levels of driving automation from "no automation" to "full automation" in order to provide clarity with respect to the usage of terminology to describe self-driving technology. ${ }^{11}$ These categories are of fundamental importance in any discussion relating to the legal implications of autonomous cars.

7 Frank Mütze et al., "Briefing: EU Strategy for Automated Mobility” (October 2018), available at https://etsc.eu/wp-content/uploads/2018-ETSC-Response-to-EU-Strategy-on-AutomatedMobility.pdf (accessed 24 August 2019).

$8 \quad$ Ibid.

9 Directive 2007/46/EC establishing a framework for the approval of motor vehicles and their trailers, and of systems, components and separate technical units intended for such vehicles, art. 20.

10 Regulation (EU) 2018/858 on the approval and market surveillance of motor vehicles and their trailers, and of systems, components and separate technical units intended for such vehicles, art. 39.

11 J3016: Taxonomy and Definitions for Terms Related to On-Road Motor Vehicle Automated Driving Systems, available at https://www.smmt.co.uk/wpcontent/uploads/sites/2/automated driving.pdf (accessed 24 August 2019). 


\begin{tabular}{|c|c|c|}
\hline SAE Level & Name & Narrative Definition \\
\hline \multicolumn{3}{|c|}{ Human driver monitors the driving environment } \\
\hline 0 & No Automation & $\begin{array}{l}\text { The full-time performance by the human } \\
\text { driver of all aspects of the dynamic } \\
\text { driving task*, even when enhanced by } \\
\text { warning or intervention systems }\end{array}$ \\
\hline 1 & Driver Assistance & $\begin{array}{l}\text { The driving mode-specific execution by a } \\
\text { driver assistance system of either steering } \\
\text { or acceleration/deceleration using } \\
\text { information about the driving } \\
\text { environment and with the expectation that } \\
\text { the human driver performs all remaining } \\
\text { aspects of the dynamic driving task }\end{array}$ \\
\hline 2 & Partial Automation & $\begin{array}{l}\text { The driving mode-specific execution by } \\
\text { one or more driver assistance systems of } \\
\text { both steering and } \\
\text { acceleration/deceleration } \\
\text { information about the driving } \\
\text { environment and with the expectation that } \\
\text { the human driver performs all remaining } \\
\text { aspects of the dynamic driving task }\end{array}$ \\
\hline \multicolumn{3}{|c|}{ Automated driving system monitors the driving environment } \\
\hline 3 & $\begin{array}{l}\text { Conditional } \\
\text { Automation }\end{array}$ & $\begin{array}{l}\text { The driving mode-specific performance by } \\
\text { an automated driving system of all aspects }\end{array}$ \\
\hline
\end{tabular}




\begin{tabular}{|l|l|l|}
\hline 4 & $\begin{array}{l}\text { of the dynamic driving task with the } \\
\text { expectation that the human driver will } \\
\text { respond appropriately to requests to } \\
\text { intervene }\end{array}$ \\
\hline High Automation & $\begin{array}{l}\text { The driving mode-specific performance by } \\
\text { an automated driving system of all aspects } \\
\text { of the dynamic driving task, even if a } \\
\text { human driver does not respond } \\
\text { appropriately to a request to intervene. }\end{array}$ \\
\hline Full Automation & $\begin{array}{l}\text { The full performance by an automated } \\
\text { driving system of all aspects of the } \\
\text { dynamic driving task under all roadway } \\
\text { and environmental conditions that can be } \\
\text { managed by a human driver. }\end{array}$ \\
\hline
\end{tabular}

*Key definitions such as dynamic driving task, driving mode and request to intervene defined in standard.

\section{Legal background}

There are several international agreements which are relevant for the development of legislation relating to autonomous vehicles. These include the Geneva Convention of the Economic Commission for Europe (ECE) of the United Nations (1958), on the uniform technical provisions for wheeled vehicles and the Vienna Convention on Road Traffic (1968). The Vienna Convention is an international treaty designed to facilitate international road safety by establishing standard traffic rules amongst the contracting parties. One of the fundamental principles of both conventions is the concept that "the driver can at 
all times control his vehicle" (Article 8(5), Vienna Convention). ${ }^{12}$ In 2016 the Vienna Convention was amended to permit autonomous driving systems provided that they comply with international regulations and can either be overridden or deactivated. ${ }^{13}$ Individual signatory states are required to translate this amendment into national laws. It is worth highlighting that this amendment is unlikely to be interpreted as enabling the adoption of highly or fully autonomous vehicles (level 4 and 5) where a driver may not be present or respond to requests to take control of the vehicle. ${ }^{14}$

Several countries that are at the forefront of the development of autonomous cars, including Japan and the USA, have only ratified the Geneva Convention and not the Vienna Convention, which is the more restrictive of the two agreements. For example, whilst Article 8 of both conventions state that every vehicle shall have a driver who should be able to control their vehicle at all times, Article 8 of the Vienna Convention additionally requires the driver to have the requisite physical and mental abilities to drive. ${ }^{15}$ It has therefore been argued that countries that have not ratified the Vienna Convention have more flexibility to adapt legislation in order to enable autonomous driving than those jurisdictions that have. ${ }^{16}$ The UK has ratified the Geneva convention and recently ratified the Vienna Convention as part of preparations for a potential no-deal

12 Vienna Convention on Road Traffic, art. 8(5).

13 Vienna Convention on Road Traffic, art. 8(5bis).

14 Dieter Lang, "Limited breakthrough for autonomous vehicles" (Taylor Wessing Download Media and Tech Law, November 2018), available at https:/www.taylorwessing.com/download/article-limited-breakthrough-for-autonomousvehicles.html (accessed 24 August 2019).

15 Vienna Convention on Road Traffic, art. 8(3).

16 Jonathan Emmanuel, "Autonomous Vehicles and the UK: Rise of the Machines" (Bird E Bird, May 2017), available at https:/www.twobirds.com/en/news/articles/2017/global/autonomous-vehicles-rise-of-themachines (accessed 24 August 2019). 
Brexit. The Vienna Convention came into force in the UK on the 28 March $2019 .{ }^{17}$ It is interesting to note that in 2018 the UK government published a policy paper (which has since been withdrawn), which states that "ratifying the 1968 Vienna Convention will not impact on the UK's ability to remain at the very forefront of automated vehicle development, testing and use."18

To enable the use of autonomous vehicles on public roads the current law in the UK, which has a focus on driver control and manual overrides, needs to evolve. The UK government wants to be at the forefront of the development of self-driving cars and stated in 2018 that it wants autonomous cars to be in use commercially by 2021. ${ }^{19}$ On 19 July 2018 the Automated and Electric Vehicle (AEV) Act 2018 received Royal Assent. This introduced a set of policies to modernise the transport system and extends the compulsory motor insurance requirement to include owners of autonomous vehicles. The main intention behind this legislation is to emphasise that if there is an insurance "event", the compensation route for the individual remains within the motor insurance settlement framework, rather than through a product liability framework against a manufacturer. The AEV Act also forces petrol station operators to install electric car charging points. This Act started life in the 2016 Queen's Speech as the Modern Transport Bill.

17 UN Treaty Collection, available at https://treaties.un.org/Pages/ViewDetailsIII.aspx?src=TREATY\&mtdsg no=XI-B19\&chapter=11> (accessed 24 August 2019).

18 Department for Transport Policy Paper, "Ratifying the 1968 Vienna Convention" (20 March 2018), available at https://www.gov.uk/government/publications/road-haulage-and-drivingin-the-eu-post-brexit/ratifying-the-1968-vienna-convention (accessed 24 August 2019).

19 Vehicle Technology and Aviation Bill, available at https://www.gov.uk/government/collections/vehicle-technology-and-aviation-bill (accessed 24 August 2019). 
In March 2018, the UK government publicised the start of a three-year review by the Law Commission of England and Wales and the Scottish Law Commission to examine any legal hurdles to the introduction of autonomous cars and highlight any areas of law requiring regulatory reform. ${ }^{20}$

\section{Testing of autonomous vehicles}

Automotive manufacturers involved in autonomous vehicle development need to test commercial vehicles on public roads prior to launch. The legal implications of autonomous vehicle testing are particularly significant given the need to test vehicles under different climatic conditions and hazardous environments at early stages in their development to ensure a robust build quality. Whilst highly automated cars are not yet available to consumers, many manufacturers such as Jaguar Land Rover have already started testing level 4 autonomous vehicles on public roads. ${ }^{21}$ It is worth noting that in practice when tests are conducted, a safety driver is present so vehicles are in fact being operated as level 2 autonomous cars (with permanent human monitoring). In 2015, the UK government conducted a review of the existing legislation regarding the testing of autonomous vehicles on public roads, and concluded that it is permissible provided that "a test driver is present and takes responsibility for the safe operation of the vehicle; and that the vehicle is used compatibly with road traffic law."22 Under these guidelines a test driver operating a car in autonomous driving mode would be responsible for any incidents and therefore needs to be

20 Ibid.

21 "Jaguar Land Rover tests driverless cars on public roads" (BBC Business, 17 November 2017), available at https://www.bbc.com/news/business-42024880 (accessed 24 August 2019).

22 Department for Transport, "The Pathway to Driverless Cars: A detailed review of regulations for automated vehicle technologies" (February 2015). 
alert and able to regain control of the car at any time.

Motor vehicle drivers owe a duty of care to other road users. The standard of care should be that of an experienced and skilled diver. In Nettleship $v$ Weston [1971] 2 QB 691, the Court of Appeal decided that the standard of care required from a learner driver was the same as that required from any other driver. It is therefore highly likely that the test driver of an autonomous vehicle would be held to the same standard as a competent driver of a non-automated vehicle. If an employee was responsible for an incident involving an autonomous vehicle under test conditions on public roads, their employer is likely to be found vicariously liable.

In July 2015, the UK Government published a "Code of Practice for Testing." 23 This provides non-statutory guidelines on safety and risk management during the testing of different categories of autonomous vehicles on public roads. Individuals involved in the testing of autonomous vehicles on public road should familiarise themselves with the code. The Department for Transport has made it clear that failure to follow the guidance outlined in the Code of Practice would be a clear indication of negligence. Adherence to the code, however, does not guarantee immunity from liability in legal proceedings. The Code of Practice is likely to have a similar status to the Highway Code during litigation. ${ }^{24}$

There are a number of key points from the Code of Practice to be noted: Vehicle requirements: Organisations must ensure all vehicles involved in testing are road-worthy, meet all relevant vehicle requirements and can be used

23 Department for Transport, "The Pathway to Driverless Cars: A Code of Practice for Testing" (July 2015), available at http://www.gov.uk/government/publications/automated-vehicletechnologies-testing-code-of-practice (accessed 22 September 2018).

24 Ibid. 
in a way that is compatible with existing road traffic laws. In particular, testing organisations need to ensure that they comply with Regulation 100 of the Construction and Use Requirements, ${ }^{25}$ which highlights that it is an offence to use a motor vehicle in a way that is dangerous to other road users. Autonomous vehicles used for testing on public roads should also be fitted with a black box for analysis in the case of an incident. Other relevant legislation includes: the Road Vehicles (Construction and Use) Regulations 1986, the Road Vehicles Authorised Weight Regulations 1998 and the Road Vehicles Lighting Regulations 1989. Testing organisations are able to use prototype vehicles which do not meet the requirement of these regulations on public roads subject to Articles 36 and 37 of the Road Vehicles (Authorisation of Special Types) (General) Order 2003. The categories of vehicles exempted are listed at Article 36(1) of this regulation as follows:

(c) any new or improved type of motor vehicle or trailer which is constructed for tests or trials;

(d) any motor vehicle which is equipped with new or improved equipment;

(e) any motor vehicle or trailer which is equipped with new or improved types of equipment.

A relevant vehicle must not be used in such a way as to cause a danger of injury to any person by reason of:
a. the condition of the vehicle, its accessories or equipment;
b. the purpose for which it is used;
c. the number of passengers carried by it;
d. the manner in which such passengers are carried;

25 The Road Vehicles (Construction and Use) Regulations 1986, SI 1986/1078. 
e. the weight, position or distribution of any load carried on the vehicle; or

f. the manner in which any such load is secured.

Maturity of technology: Any highly or fully automated vehicles to be tested on public roads must first be subjected to in-house testing on closed roads or test tracks by the test organisation.

Test drivers: Testing organisations should ensure that they have robust risk management, process and training procedures in place for test drivers and operators and should ensure that they hold the appropriate UK driving license. The driver must be able to regain control of the vehicle at any time. The guidelines also suggest that drivers maintain a gaze and focus that is comparable to the position adopted by a driver of a standard vehicle to avoid alarming other road users.

Cyber security: Vehicle manufacturers and component suppliers will be responsible for ensuring that autonomous vehicles being tested on public roads have appropriate levels of security to manage any risk of unauthorised access (i.e. "hacking"). Testing organisations should consider adopting the security principles set out in the BSI PS754 Software Trustworthiness - Governance and management specification or an equivalent specification.

Engagement with local emergency services: The Code of Practice recommends that those wishing to conduct testing of highly and fully automated vehicles on the road should engage with the local emergency services. Wherever possible, testing organisations should establish a single point of contact with the police. It is also recommended that they provide the vehicle registrations of the vehicles undergoing testing to the police service. Testing organisations are advised to provide relevant technical briefings to the police service, for example, they may wish to brief the police service on how to disable autonomous vehicles. 


\section{Liability}

At present, claims resulting from road traffic accidents are predominantly brought in negligence. A driver that fails to exercise due care can be found liable in negligence for losses arising as a consequence of the accident. Claims involving multiple vehicles may involve contributory negligence. In the UK there is a compulsory motor insurance system, such that drivers are liable for losses arising from accidents in the first instance but are required to have third party liability insurance. Under the current system, when an accident is caused by a defect in the car, drivers may claim against the vehicle manufacturer or a component supplier.

One of the major unknown legal implications surrounding autonomous cars is how the courts will apportion liability in the case of collisions. The development of increasingly autonomous vehicles is likely to steer liability from personal towards product liability. There are a number of potential parties involved in claims following accidents including; automotive manufacturers, fleet operators/service providers, software manufacturers, local government with responsibility for maintaining the infrastructure and drivers. Furthermore, several different types of claim could potentially be brought following a collision involving a semi-autonomous or autonomous vehicle including; product liability claims, breach of contract, negligence and misrepresentation. There is currently some ambiguity surrounding this area of law. Each of these types of claim will be addressed in turn.

\section{Product Liability}

Product liability is the legal liability incurred by a manufacturer as a consequence of selling a defective product. In a recent publication titled "The Law and 
Autonomous Vehicles," ${ }^{26}$ Lucy McCormick emphasises that the liability position of the courts in England and Wales is likely to be dependent on the level of automation of the vehicle.

If a "level 2" vehicle is involved in an accident, the driver is highly likely to be held liable for the collision due to the expectation that the driver remains alert and in control of most aspects of the dynamic driving task. In cases where the failure of Advanced Driver Assistance System (ADAS) contributed to the crash, there may be some scope for the driver to bring a claim against the manufacturer. The driver of the vehicle is most likely to bring a claim against the manufacturer for product liability under the Consumer Protection Act (CPA 1987), or potentially sue the manufacturer for breach of contract or negligence. ${ }^{27}$

The courts will need to take a view on the apportionment of liability when level 3 autonomous vehicles are involved in a collision. In level 3 vehicles, the car is able to actively monitor the environment. Whilst in principle the driver should be able to respond to any requests to intervene, the courts will need to decide the extent to which the driver is responsible for monitoring a car in self-driving mode and how quickly they can be expected to regain control of the vehicle when prompted. A recent study based on vehicle and eye-tracking measurements showed that drivers take approximately 15 seconds to resume control and 40 seconds to stabilise the vehicle. ${ }^{28}$ Analysis of the responses to a recent automated vehicle consultation by the Law Commission on new rules for the UK's self-

26 Matthew Channon, Lucy McCormick, Kyriaki Noussia, The Law and Autonomous Vehicles (Informa Law from Routledge, 2019).

27 Ibid.

28 Natasha Merat et al., "Transition to Manual: Driver behaviour when resuming control from a highly automated vehicle" (2014, vol. 27, part B), Transportation Research Part F: Traffic Psychology and Behaviour, available at https://www.sciencedirect.com/science/article/pii/S1369847814001284 (accessed 24 August 2019). 
driving future demonstrated that issues surrounding level 3 autonomous vehicles are currently controversial. Approximately half of all consultees thought there should be no relaxation of the laws against distracted drivers of level 3 vehicles. ${ }^{29}$

The new Audi A8 is the first production car to achieve level 3 autonomy, however, it is not possible to activate the self-driving features in the UK due to current legislation. It features an artificial intelligence (AI) driver assistance scheme known as Traffic Jam Pilot, which is capable of controlling all necessary driving functions up to a speed of $37 \mathrm{mph} .{ }^{30}$ The use of this technology is currently prohibited by Regulation 104 of the Road Vehicles (Construction and Use) Regulations 1986, which states "no person shall drive or cause or permit any other person to drive, a motor vehicle on a road if he is in such a position that he cannot have proper control of the vehicle or have a full view of the road and traffic ahead." 31 The Department for Transport (DfT) is currently involved in a three year project with the Law Commission to set out proposals for a long-term regulatory framework for self-driving vehicles. In a consultation in July 2016 titled, "The Pathway to Driverless cars: Proposals to Support Advanced Driver Assistance Systems and Automated Vehicle Technologies," 32 the Centre for

29 Law Commission, “Law Commissions' analysis of responses to automated vehicle consultation points to the way forward" (June 2019), available at https://www.lawcom.gov.uk/law-commissions-analysis-of-responses-to-automated-vehicleconsultation-points-to-the-way-forward/ (accessed 24 August 2019).

30 Matt de Prez, "Legislation puts brakes on Audi's Level 3 autonomous technology" (Fleet News, 15 February 2018), available at https://www.fleetnews.co.uk/news/manufacturernews/2018/02/15/legislation-puts-brakes-on-audi-s-level-3-autonomous-technology (accessed 24 August 2019).

31 Consumer Protection Act (CPA) 1987, s 1(2)(c).

32 Department for Transport, Centre for Connected \& Autonomous Vehicles, "Pathway to Driverless Cars: Proposals to support advanced driver assistance systems and automated vehicle technologies" (July 2016), available at $<$ https://assets.publishing.service.gov.uk/government/uploads/system/uploads/attachment data/file/536365/driverless-cars-proposals-for-adas-and avts.pdf (accessed 24 August 2019). 
Connected and Autonomous Vehicles at the DfT sought to amend Regulation 104. At present, this regulation has not been amended, however in a more recent consultation it was noted that there is a case for future amendment. ${ }^{33}$ The German government has already adopted regulatory changes allowing the use of Level 3 systems, therefore consumers are already able to benefit from this technology in Germany.

It is highly likely that the manufacturer would be considered liable for incidents involving highly automated level 4 or 5 autonomous cars, since the driver is not expected to be required to intervene with such systems. The vehicle manufacturer may, however, in turn claim against third parties such as the software provider or suppliers.

\section{Product Liability under the Consumer Protection Act (CPA) 1987}

The majority of claims for product liability are brought under the CPA 1987. This implements European Council Directive 85/374/EEC (the Product Liability Directive $)^{34}$ and is to be construed in accordance with that directive. It creates a form of strict liability for damage caused by defective products. Liability under this act applies to all consumer goods and goods used at places of work. ${ }^{35}$ Under this act, a product is defined as "any goods or electricity and ....includes a

33 Department for Transport, Centre for Connected \& Autonomous Vehicles, "Remote Control Parking and Motorway Assist: Proposals for Amending Regulations and the Highway Code" (December 2017) s. 1.24-1.26, available at https://assets.publishing.service.gov.uk/government/uploads/system/uploads/attachment d ata/file/669442/remote-control-parking-motorway-assist-proposals-for-amending-regulationand-highway-code.pdf (accessed 24 August 2019).

34 Council Directive 85/374/EEC of 25 July 1985 on the Approximation of the Laws, Regulations and Administrative Provisions of the Member States Concerning Liability for Defective Products OJ 1985 L 210/29.

35 Consumer Protection Act (CPA) 1987. 
product which is comprised in another product, whether by virtue of being a component part or raw material or others."36 Both the components of autonomous cars and the entire system would be classed as products under this act. The question of whether "software" can fall within the definition of a product has stimulated significant debate. ${ }^{37}$ The CPA 1987 was not drafted to cover "pure information". The general consensus on this point following the implementation of the CPA 1987 was that, in the event of a defect in software leading to physical damage, liability would rest with the producer of the complete system. ${ }^{38}$ There remains, however, some divergence of opinion as to whether software that may endanger persons if defective, can be incorporated within the definition of product. ${ }^{39}$ Whilst it is likely that an autonomous car purchased with software installed would be considered a product, there is some uncertainty surrounding how the courts would treat "Over-the-Air" software updates such as those currently used by Tesla. ${ }^{40}$

The meaning of the term "defect" is defined at Section 3(1) of the CPA 1987: "if the safety of the product is not such as persons are generally entitled to expect". There is some guidance at Section 3(2) of the statute as to what persons are "generally entitled to expect". In her book on the legal implications of autonomous cars ${ }^{41}$, Lucy McCormick highlighted that the dicta of Hickinbottom $\mathrm{J}$ in Wilkes $v$ DePuy International Limited is likely to be particularly helpful in the

\footnotetext{
36 Ibid., s. 1(2)(c).

37 Diane Rowland and Elizabeth Macdonald, Information Technology Law, 5th ed., (Routledge, 2016), p. 220.

38 Ibid.

39 Ibid., p. 220-226.

40 Gene Carter, "Why Don't More Cars Update Their Software Automatically" (OnBoardSecurity, 20 September 2017), available at http://blog.onboardsecurity.com/blog/why-dont-more-cars-update-their-softwareautomatically (accessed 24 August 2019).

41 Ibid.
} 
interpretation of the CPA 1987 for collisions involving autonomous cars. He wrote that

in considering whether a product suffered from a defect, the court must assess the appropriate level of safety, exercising its judgement, and taking into account the information and the circumstances before it, whether or not an actual or notional patient, or patients, would in fact have considered each of those factors and all of that information.

This is likely to be applicable where consumers have unrealistic expectations on autonomous vehicles.

Six statutory defences are listed in Section 4 of the CPA 1987, the most relevant of these for autonomous vehicles being the "development risks" defence, also known as the "state of the art" defence (Section 4(1)(e)). This defence can be successfully deployed if the defendant is able to prove that

the state of scientific and technical knowledge at the relevant time was not such that a producer of products of the same description as the product in question might be expected to have discovered the defect if it had existed in his products under their control. ${ }^{42}$

Expressed differently, where a discovery is made after a product is put into circulation, such that it would now be considered to be defective, the manufacturer should not be held liable. ${ }^{43}$ The defence of contributory negligence can also be used as a defence to claims under the CPA 1987.

The application of the CPA 1987 to autonomous cars does have certain limitations. Firstly, the CPA 1987 makes no provision for liability for damage to

\footnotetext{
42 Consumer Protection Act (CPA) 1987, s 4(1)(e).

43 Kirsty Horsey and Erika Rackley, Tort Law, 6th ed. (OUP, 2019), p. 374.
} 
the defective product itself. The repair of autonomous cars is likely to cost substantially more than existing mid-range motor vehicles due to the cost of parts such as sensors. Secondly, there is a 10-year long stop provision. An action cannot be brought more than 10-years after the "relevant time" (Section 11A(3) Limitation Act 1980). The "relevant time" is defined by Section 4 CPA as when the product was last supplied by someone who is a "primary defendant". The courts may need to address whether the limitation period is applied strictly in the context of autonomous cars where the vehicle lifetime may be considerably longer than 10-years. ${ }^{44}$ Those with an interest in this field should be aware of these limitations of the CPA 1987 and alert to any modifications to the legislation designed to enable the statute to be applied to evolving product categories such as autonomous vehicles.

At present, there is little case law in England and Wales to clarify the position courts are likely to take on the apportionment of liability following collisions. In 2016, there was a fatal collision as a result of the autopilot system on a Tesla Model S vehicle failing to recognise a white tractor-trailer turning in front of a driver's car onto a highway against a bright sky. Tesla successfully argued that customers need to maintain alertness whilst driving in auto-pilot mode. ${ }^{45}$ A report by the US federal government into this accident cleared the autopilot system of any fault, however, it was commented that Tesla could have been more specific about the limitations of its autonomous driving functions. ${ }^{46}$

44 Matthew Channon, Lucy McCormick, and Kyriaki Noussia, The Law and Autonomous Vehicles 1st ed., (Informa Law from Routledge, 2019).

45 Danny Yadron and Dan Tynan, "Tesla driver dies in first fatal crash whilst using autopilot mode" (The Guardian, 1 July 2016), available at https://www.theguardian.com/technology/2016/jun/30/tesla-autopilot-death-self-driving-carelon-musk (accessed 24 August 2019).

46 National Transportation Safety Board (NTSB), “Accident Report NTSB/MAR-17/02 PB2017102600" (7 May 2016), available at 


\section{Actions automotive manufacturers may undertake}

Manufacturers developing autonomous vehicles should take several steps to help defend their position as the legislation and position of the courts surrounding product liability and autonomous vehicles evolves. Automotive manufacturers should ensure they are fully aware of upcoming legislation and regulatory hurdles. It is likely that the regulatory issues will serve as a significant gating function as to which technologies and models come to market. Communication between legal and technical departments may be necessary to position the launch of more highly automated vehicles in sync with legislative changes that enable the use of the technology. When manufacturing level 3 autonomous cars, automotive manufacturers should ensure the adequacy of the automated warning system and interface that prompts the operator to retake control of the vehicle since this is an issue which will likely arise in product liability claims. In order to limit manufacturer liability, automotive manufacturers may wish to develop technology that incorporates override options (e.g. manual driving) even in level 4 or 5 autonomous cars, because in situations where drivers interact and are able to control the vehicle, it will be easier to argue contributory negligence in the event of a collision.

\section{Contractual liability}

A purchaser of an autonomous vehicle who is seeking to bring a contractual claim is likely to rely on the provisions of the Consumer Rights Act (CRA) 2015, ${ }^{47}$ which applies to all contracts entered into after 1st October 2015. Under the CRA

https://www.ntsb.gov/investigations/AccidentReports/Reports/HAR1702.pdf (accessed 24 August 2019).

47 Consumer Rights Act (CRA) 2015. 
2015, goods must be of satisfactory quality, fit for purpose and as described. Contractual claims are usually only relevant when there is a direct contractual relationship between the parties and would normally be brought against the retailer and not the manufacturer. Third parties involved in an accident with an autonomous vehicle would therefore not usually be able to bring a claim. The limitation period for contractual claims is six years from the date of breach. The purchaser of an autonomous vehicle is more likely to rely on the CPA 1987.

\section{Negligence}

To succeed in a claim for negligence, the claimant must establish that the defendant owed a duty of care to the claimant; that the defendant breached that duty of care; that the breach of care caused damage to the claimant and that the damage was reasonably foreseeable. In assessing whether the manufacturer of an autonomous car owes a duty of care to the user, the courts are likely to keep in mind that "a car is potentially a dangerous weapon." 48 In most cases the type of damage caused by autonomous vehicles such as injury to users and property is likely to be sufficiently foreseeable to give rise to a claim in negligence. To give rise to a claim in negligence there must be personal injury or damage to property. Pure economic loss does not give rise to a claim in negligence. ${ }^{49}$

\section{Insurance law implications}

In the early 20th Century, Great Britain was a motoring pioneer and by World

48 Lunt v Kelifa (2002) EWCA Civ 801 at [20] per Latham LJ.

49 Bryan M.E.McMahon and William Binchy, Law of Torts, 4th ed. (Bloomsbury Professional, 2013). 
War II there were approximately two million cars on roads in the UK. ${ }^{50}$ As roads became busier and the number of accidents increased, the government was forced to take action leading to the Road Traffic Act of 1930. ${ }^{51}$ Amongst many new laws, this led to the introduction of compulsory third-party insurance. Currently all vehicles have to be insured under Section 143 of the Road Traffic Act $1988 . .^{52}$ The insurance must cover third party risks as set out in Section 145(3)(a) of the Act. Under the current driver-centric motor insurance framework, the insurance premium paid by a driver is determined by a number of factors including the claims history of the driver. Following a claim, efforts are normally taken to determine which driver was "at fault", with the insurer of the "at fault" driver paying for the majority of the claim. When an uninsured or unknown driver is involved in an accident, victims are compensated through the Motor Insurer's Bureau (MIB). The MIB is funded through a levy on motor insurers operating in the UK. ${ }^{53}$

At present, human error is a factor in $95 \%$ of all road accidents ${ }^{54}$ and there is substantial evidence that the number of serious accidents is reducing due to the increasing automation of vehicles on the road. ${ }^{55}$ This could potentially fuel a

50 Simon Gunn, "The history of transport systems in the UK, Future of mobility: Evidence Review" (Foresight Project, Government Office for Science, December 2018), available at https://www.gov.uk/government/collections/future-of-mobility (accessed 24 August 2019).

51 Road Traffic Act, 1930.

52 Road Traffic Act 1988, s. 143.

53 Özlem Gürses, The Law of Compulsory Motor Vehicle Insurance (Informa Law from Routledge, 2020), ch. 10.

54 The Royal Society for the Prevention of Accident (ROSPA), "Road Safety Factsheet", available at https://www.rospa.com/rospaweb/docs/advice-services/road-safety/roadcrashes-overview.pdf (accessed 24 August 2019).

55 National Highway Traffic Safety Administration (NHTSA), US Department for Transport (DOT), “DOT HS 812442, Automated Driving System 2.0: A Vision for Safety” (September 2017), available at https://www.nhtsa.gov/sites/nhtsa.dot.gov/files/documents/13069aads2.0 090617 v9a tag.pdf (accessed 24 August 2019). 
reduction in premiums and a decline in profits for the motor insurance industry, ${ }^{56}$ however the repair of autonomous cars is likely to be more expensive and recent reports have shown that initially the motorists' habits may worsen and they may become more prone to take risks as the degree of autonomy of cars increases. As a consequence, in the short term, there may be an initial increase in the number of road traffic accidents, increasing insurance premiums for those driving conventional cars. ${ }^{57}$ Autonomous cars are likely to harvest significantly more data than conventional vehicles and the rise of connectivity combined with cameras and sensors on cars is likely to reduce the role of the Motor Insurance Bureau (MIB). Whilst the MIB would probably have to cover claims against uninsured, unregistered autonomous cars, incidents of this nature are likely to be relatively few and far between, which could reduce premiums for drivers..$^{58}$

\section{Automated and Electric Vehicles (AEV) Act}

The key feature of the insurance framework for autonomous cars outlined in the $\mathrm{AEV}$ Act is that it extends the compulsory insurance requirements to owners of autonomous vehicles, making it mandatory for the owner to ensure that there is an insurance policy in place which covers the manufacturers' and any other entities' product liability. This additional compulsory product liability insurance is required to cover injuries to the "not at fault" automated vehicle driver as well

56 Helen Robinson, "Who's in the driving seat? Driverless cars, liability and insurance" (Taylor Wessing Download Media \& Tech Law, December 2017), available at https://www.taylorwessing.com/download/article-whos-in-the-driving-seat.html (accessed 24 August 2019).

57 Automobile Association (AA) Developments Ltd "The future of driverless car insurance", available at https://www.theaa.com/car-insurance/advice/driverless-cars (accessed 24 August 2019).

58 Matthew Channon, “Look, No Hands!” (2016) The New Law Journal. 
as passengers and third parties. ${ }^{59}$ Given the significance of the AEV Act and the uncertainty surrounding the development of the technology, it is worth examining each section of the Act.

Section 1 of the Act provides for registration of vehicles designed or adapted to be capable of "driving themselves" for use in public places by the Department of Transport. The Secretary of State will maintain a list of automated vehicles. This will enable manufacturers and insurers to have certainty as to whether the legislation applies to a specific vehicle. During the passing of this Act, Baroness Sugg, former Parliamentary Under Secretary of State for Transport ${ }^{60}$ stated that the Department for Transport are working with the DVLA to define the form and nature of this list. ${ }^{61}$ It is anticipated that the list of vehicles will draw on either international or domestic standards. This section of the Act is currently drafted very broadly, because the technology is still under development and it is not yet possible to identify suitable standards. ${ }^{62}$

Section 2 of the AEV Act sets out the liability of insurers in the event of an accident. It is clear from this section that when a car driving in autonomous mode is involved in an accident, the first instance liability rests with the insurer and the claim follows a traditional insurance route, rather than a direct product liability action. This legislation is likely to benefit consumers because any claims between

59 Louise Butcher and Tim Edmonds, "Commons Briefing Papers CBP-8118: Automated and Electric Vehicles Act 2018", (House of Commons Library, 15 August 2018), available at https://researchbriefings.parliament.uk/ResearchBriefing/Summary/CBP-8118 (accessed 24 August 2019).

60 "Baroness Sugg CBE", available at https://www.gov.uk/government/people/baroness-sugg (accessed 24 August 2019).

61 Baroness Sugg, "Letter on Automated and Electric Vehicle Act” (7 March 2018), available at http://data.parliament.uk/DepositedPapers/files/DEP20180254/Letter from Baroness Sugg Automated and Electric Vehicles Bill.pdf (accessed 24 August 2019).

62 Ibid. 
insurers and actions taken by insurers against manufacturers will be secondary claims and consumers will not therefore have to wait for the action of these outcomes before receiving compensation. The limit to the liability is the same as the $£ 1.2$ million limit that applies in "normal" motor insurance claims under Section 145 of the 1988 Act. Section 5 follows directly from Section 2 and highlights the insurer's right to make a secondary claim against the manufacturer where it is believed they are responsible for the accident.

Section 3 outlines the provisions for contributory negligence. The most significant provision in this section for automotive clients is that the insurer or owner of the automated vehicle is not liable when there is an accident if the operator of the vehicle was negligent in allowing the vehicle to begin driving itself when it was not appropriate to do so.

Under Section 4 of the AEV Act, the liability of the insurer is limited where there is a failure to install safety-critical software updates that the insured person knows are safety critical or where software alterations are made with the insured person's knowledge that are prohibited under the policy.

Whilst it is clear that the insurance provisions of this act are drafted in relation to highly automated (level 4 and 5) autonomous vehicles, it is unclear where the boundaries of the act lie and whether some borderline vehicles could fall under the scope of this act. There are currently some uncertainties as to the parameters of the legislation and those with an interest in this field should remain up to date with case law as this emerges. Some authors have commented on the lack of clarity and breath of this Act. ${ }^{63}$ It is noteworthy that this Act is one of the only examples where the legislation significantly predates the technology, in strong contrast to the Road Traffic Act 1930, which was introduced after decades

63 Lucie Clinch and Julian Chamberlayne, "The unanswered questions following the Automated and Electric Vehicles Act 2018" (Personal Injury (PI) Focus, October 2018). 
of injustice to victims where the legislation had not caught up with the development of the technology. Clearly, early adoption of legislation has many advantages, however, there is a risk the legislation will be subject to significant amendments by the courts. ${ }^{64}$ The legislation will be subject to a report to Parliament after two years in operation. ${ }^{65}$

\section{Conclusions}

The introduction of autonomous cars will undoubtedly be one of the most significant technological developments of the 21st Century. With autonomous, connected and electric vehicles on the horizon, it is likely that we will see an increase in the volume and complexity of litigation involving automotive manufacturers. Many of the new technologies being integrated into autonomous vehicles, such as complex software and security features, have been developed in other sectors by technology companies who are more willing to use litigation to defend their reputation and innovations than traditional automotive manufacturers. ${ }^{66}$

This article has highlighted the significant volume of emerging legislation across jurisdictions, which automotive manufacturers and suppliers must navigate as they test and launch vehicles equipped with increasingly autonomous driving systems. It has also discussed some of the key legal barriers and areas in which the legal framework must develop to enable the launch of autonomous cars.

64 Matthew Channon, “The Automated and Electric Vehicles Bill: Right place, wrong time?" (London, February 2017).

65 Automated and Electric Vehicles Act 2018, s. 19(4).

66 Allen \& Overy, "Autonomous and connected vehicles: navigating the legal issues" (2017), available at http://www.allenovery.com/SiteCollectionDocuments/Autonomous-andconnected-vehicles.pdf (accessed 24 August 2019). 